\title{
Impact of capsular incision on biochemical recurrence after radical perineal prostatectomy
}

\author{
KW Kwak ${ }^{1}$, HM Lee ${ }^{2}$ and HY Choi ${ }^{2}$ \\ ${ }^{1}$ Department of Urology, KEPCO (Korea Electric Power Corporation) Medical Foundation, Hanil General Hospital, Seoul, Korea and \\ ${ }^{2}$ Department of Urology, Samsung Medical Center, Sungkyunkwan University School of Medicine, Seoul, Korea
}

\begin{abstract}
The prognostic implications of capsular incision (CI) remain to be defined. We evaluated the impact of CI on biochemical recurrence (BCR) and the potential risk factors of CI. Between June 1995 and July 2007, 266 patients with follow-up for at least 6 months, who had neither the seminal vesicle nor lymph node involvement on prostatectomy specimen, were included. Patients with insufficient biopsy data and those with neoadjuvant and/or adjuvant therapy were excluded. CI was defined as tumor extending into the inked margins, at sites except the apex of the prostate, without documented extraprostatic extension (EPE). There were 186 with organ-confined disease and negative surgical margins (pT2/SM-), 12 with organ-confined disease and an apex-only positive margin (pT2/AM +), 35 with CI, 19 with EPE and negative surgical margins (pT3a/SM-) and 13 with EPE and positive surgical margins ( $\mathrm{pT} 3 \mathrm{a} / \mathrm{SM}+$ ). We compared BCR-free probability among these five groups and the risk factors for CI were assessed. The 3-year BCR-free probability for each group was $92.7 \%$ for pT2/SM-, $75.8 \%$ for pT2/AM +, $70.7 \%$ with CI, $84 \%$ with pT3/SM- and $51 \%$ in pT3/SM + . That for CI was worse than pT2/SM- $(P=0.007)$, not significantly different from pT2/AM + and pT3/SM- $(P=0.614, P=0.318$, respectively $)$, but better than pT3/SM $+(P=0.044)$, adjusting for the pre-operative prostate-specific antigen and pathological Gleason score. The risk for CI was significantly associated with more than $25 \%$ positive biopsy cores. CI seems to affect BCR and is more likely to occur in proportion to positive biopsy cores.

Prostate Cancer and Prostatic Diseases (2010) 13, 28-33; doi:10.1038/pcan.2009.19; published online 2 June 2009
\end{abstract}

Keywords: capsular incision; radical perineal prostatectomy

\section{Introduction}

Radical prostatectomy is considered to be the most reliable method of eradication of localized prostate cancer. Radical perineal prostatectomy (RPP), described by Young in $1905,{ }^{1}$ has been widely abandoned in favor of the retropubic approach, which allows for a simultaneous pelvic lymphadenectomy. With the advent of laparoscopic lymphadenectomy for staging purposes, and later prostate-specific antigen (PSA) testing to predict lymph node involvement, the perineal approach has gained renewed interest for minimal access surgery with decreased morbidity and shorter hospitalization. As Weldon $^{2}$ described the nerve-sparing RPP, several studies have reported that the pathological and functional results of RPP are comparable to the retropubic approach. $^{3-6}$

The pathological classification of the prostate following radical prostatectomy provides important prognostic

Correspondence: Professor HY Choi, Department of Urology, Samsung Medical Center, Sungkyunkwan University School of Medicine, \#50, Irwon-dong, Gangnam-gu, Seoul 135-710, Korea. E-mail: hanchoi@skku.edu

Received 9 December 2008; revised 10 March 2009; accepted 13 March 2009; published online 2 June 2009 information; an accurate pathology report is the cornerstone to cancer treatment and follow-up. ${ }^{7,8}$ In addition to the pre-operative serum PSA, Gleason score on pathology specimen, the seminal vesicle invasion and lymph node status, and a positive surgical margin with extraprostatic extension (EPE) are significant predictors of clinical and biochemical recurrence (BCR). ${ }^{9-13}$ However, the prognostic implication of capsular incision (CI), tumor extending to the inked margins without a histologically documented EPE, remains to be defined. Most of the earlier studies evaluated the retropubic approach. At most urological training centers RPP has not routinely been carried out; there have been few studies on CI with RPP. Therefore, we evaluated the impact of $\mathrm{CI}$ on $\mathrm{BCR}$ and risk factors for $\mathrm{CI}$ in men undergoing RPP.

\section{Methods}

\section{Patient population}

A total of 520 men underwent RPP for localized prostate cancer between June 1995 and July 2007. Among them, 266 patients treated with RPP by a single surgeon (HYC), who had follow-up for at least 6 months were included 
in this study. Patients with insufficient biopsy data, neoadjuvant hormone therapy, positive lymph nodes or seminal vesicle involvement and immediate adjuvant treatment were excluded from the study. The hospital ethics committee approved this study. All patients underwent complete medical examinations and serum PSA test with the use of the ADVIA Centaur PSA assay (Bayer Diagnostics, Tarrytown, NY, USA). If clinically indicated, prostate magnetic resonance imaging and bone scan were carried out for pre-operative staging workup. Pelvic lymph node dissection (PLND) was not routinely carried out. Twelve $(4.5 \%)$ patients underwent PLND with a mini-laparotomy or laparoscopy because of high PSA and Gleason score. The percentage of positive biopsy cores on biopsy specimen was calculated as the number of cores that contained cancer divided by the number of cores sampled. All biopsy specimens were reviewed by uropathologists at our institution. The mean patient age at prostatectomy was 63.8 (range, 43-78 years). Nerve-sparing RPP (40 bilateral and 56 unilateral) was carried out in 96 patients $(36.1 \%)$. None of the patients had clinical evidence of distant metastasis at radical prostatectomy. The prostate volume was measured by transrectal ultrasound (TRUS). BCR was defined as two consecutive increases in PSA of $0.2 \mathrm{ng} \mathrm{ml}^{-1}$ or greater.

\section{Radical prostatectomy specimens}

Routine pathological examination was carried out on the RPP specimens by sectioning and totally submitting the prostate tissue. The prostates were inked to determine the surgical margins and fixed overnight in $10 \%$ buffered formalin. The apical segment and basal portion were removed and serially sectioned at $3-\mathrm{mm}$ intervals in a plane perpendicular to the prostatic urethra. Gleason score, pathological stage, tumor volume and surgical margins were assessed by the uropathologists. CI was defined as tumor extending into the inked margins, at sites except the apex of the prostate, without documented EPE. We separated organ-confined disease with apex-only positive margins (pT2/AM+) from $\mathrm{CI}$, as the prostatic capsule is not well-defined at the apex of the prostate and the histological boundaries of this region are extremely vague. The mapping of CI was performed based on the classification in the apex, posterolateral, anterior and base. The tumor volume of the RPP specimen was determined as the percentage of the prostate gland with cancer, by quantifying the number of blocks of radical prostatectomy tissue with cancer. The pathological stage was categorized according to the 2002 American Joint Committee on Cancer guidelines. All cases were subdivided into five groups including: (i) organ-confined disease and negative surgical margins (pT2/SM-), (ii) organ-confined disease and an apex-only positive margin (pT2/AM+), (iii) organ-confined disease with positive surgical margins, except the apex of the prostate (CI), (iv) EPE and negative surgical margins (pT3a/SM-) and (v) EPE and positive surgical margins ( $\mathrm{pT} 3 \mathrm{a} / \mathrm{SM}+)$.

\section{Statistical analysis}

The differences in the pre-operative PSA and Gleason score on pathology among the five groups were assessed by the Kruskal-Wallis test and the Fisher's exact test. The probability of freedom from BCR was estimated using the Kaplan-Meier method. The multivariate Cox proportional hazard analysis was used to compare the BCR rate of CI to other groups, adjusting for the pre-operative PSA and RPP Gleason score. Analysis of the occurrence of CI in patients with organ-confined disease was on the basis of logistic regression with adjustment for the preoperative PSA, biopsy Gleason score, prostate volume, the percentage of positive biopsy cores, the surgical approach (nerve-sparing versus wide excision) and the number of case experienced. To calculate the incidence of CI with increasing surgical experience, a logistic regression model was used with CI as the dependent variable and the number of cases as the predictor. All tests were two-sided, with a $P<0.05$ considered statistically significant. SPSS 13.0 (SPSS Inc, Chicago, IL, USA) was used for the statistical analyses.

\section{Results}

Among the 266 men included in the study, 186 (69. 9\%) were pT2/SM-, $12(4.5 \%)$ were pT2/AM +, $35(13.2 \%)$ had CI, $19(7.1 \%)$ were pT3a/SM- and $14(5.3 \%)$ were pT3a/SM + . Among the patients with CI, 24 (68.6\%) had a single area of CI and 11 had two different areas. The majority $(87.5 \%)$ of men with a single CI had positive surgical posterolateral margins and the rest were positive at the base of the prostate. The cases with CI at the apex or anterior margin of the prostate had positive margin at the other site. The pre-operative median PSA in each group was $6.97,6.53,7,7.49$ and $12.1 \mathrm{ng} \mathrm{ml}^{-1}$, respectively; the differences were statistically significant $(P=0.004)$. The distribution of Gleason score on pathology was also significantly different in the comparisons among the five groups (Table 1). The mean follow-up was 36 months (6-128) in all patients. The 3-year BCRfree probability was $92.7 \%$ in pT2/SM- group, $75.8 \%$ in pT2/AM + group, $70.7 \%$ in the CI group, $84 \%$ in pT3a/ SM- group and $51 \%$ in $\mathrm{pT} 3 \mathrm{a} / \mathrm{SM}+$ group (Figure 1). A comparison of the occurrence of $\mathrm{BCR}$ in the CI group to that of the other groups showed that the men with CI had a higher likelihood of BCR than did the men with pT2/SM- $(P<0.0001)$, were comparable with those with $\mathrm{pT} 2 / \mathrm{AM}+$ and $\mathrm{pT} 3 \mathrm{a} / \mathrm{SM}-(P=0.614$ and 0.318$)$, but better than those with $\mathrm{pT} 3 \mathrm{a} / \mathrm{SM}+(P=0.044)$, after adjusting for the pre-operative PSA and Gleason score on the pathology (Table 1).

Thirty-five men out of the 233 with organ-confined (pT2) disease had CI in the RPP specimens. When the pre-operative PSA, biopsy Gleason score, surgical approach (nerve-sparing versus wide excision), prostate volume, the number of case experienced and the percentage of positive biopsy cores were considered in the analysis, the surgical approach, prostate volume, the number of case experienced and the percentage of positive biopsy cores were associated with CI on the univariate analysis. However, the multivariate analysis showed that the number of case experienced and the percentage of positive biopsy cores was the only significant independent predictor of CI with RPP (Table 2). Assessing the incidence of CI over time with RPP showed that the incidence of CI decreased over time 
Table 1 Clinical, pathological features and biochemical recurrence by pathological groups

\begin{tabular}{|c|c|c|c|c|c|c|}
\hline \multirow[t]{2}{*}{ Variables } & \multicolumn{5}{|c|}{ Groups by RPP pathology } & \multirow[t]{2}{*}{ P-value } \\
\hline & $p T 2 / S M-$ & $p T 2 / A M+$ & $C I$ & pT3a/SM- & pT3a/SM+ & \\
\hline Number of points & 186 & 12 & 35 & 19 & 14 & \\
\hline Median PSA ng ml ${ }^{-1}$ (range) & $6.97(1.3-37.6)$ & $6.5(4.1-24.6)$ & $7.0(4.1-60.6)$ & $7.49(2.9-23.3)$ & $12.1(3.8-39.5)$ & $0.004^{\mathrm{a}}$ \\
\hline \multicolumn{7}{|l|}{ Gleason score } \\
\hline$\leqslant 6$ & 70 & 1 & 9 & 3 & 2 & \multirow[t]{6}{*}{$0.009^{\mathrm{b}}$} \\
\hline 7 & 90 & 10 & 15 & 14 & 5 & \\
\hline$\geqslant 8$ & 26 & 1 & 11 & 2 & 7 & \\
\hline Number of BCR (\%) & $15(8)$ & $2(16.7)$ & $10(28.6)$ & $2(10.5)$ & $7(50)$ & \\
\hline $\begin{array}{l}\text { Adjusted HR versus capsular } \\
\text { incision ( } 95 \% \text { Confidence Interval) }\end{array}$ & $0.312(0.155-0.643)$ & $1.170(0.446-3.758)$ & 1.0 & $0.697(0.147-3.303)$ & $1.374(1.158-4.063)$ & \\
\hline$P$-value & $<0.0001$ & 0.614 & & 0.318 & 0.044 & \\
\hline
\end{tabular}

Abbreviations: BCR, biochemical recurrence; CI, capsular incision; HR, Hazard ratio; PSA, Prostate-specific antigen.

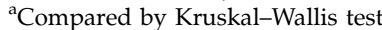

${ }^{\mathrm{b} C o m p a r e d}$ by Fisher's exact test.

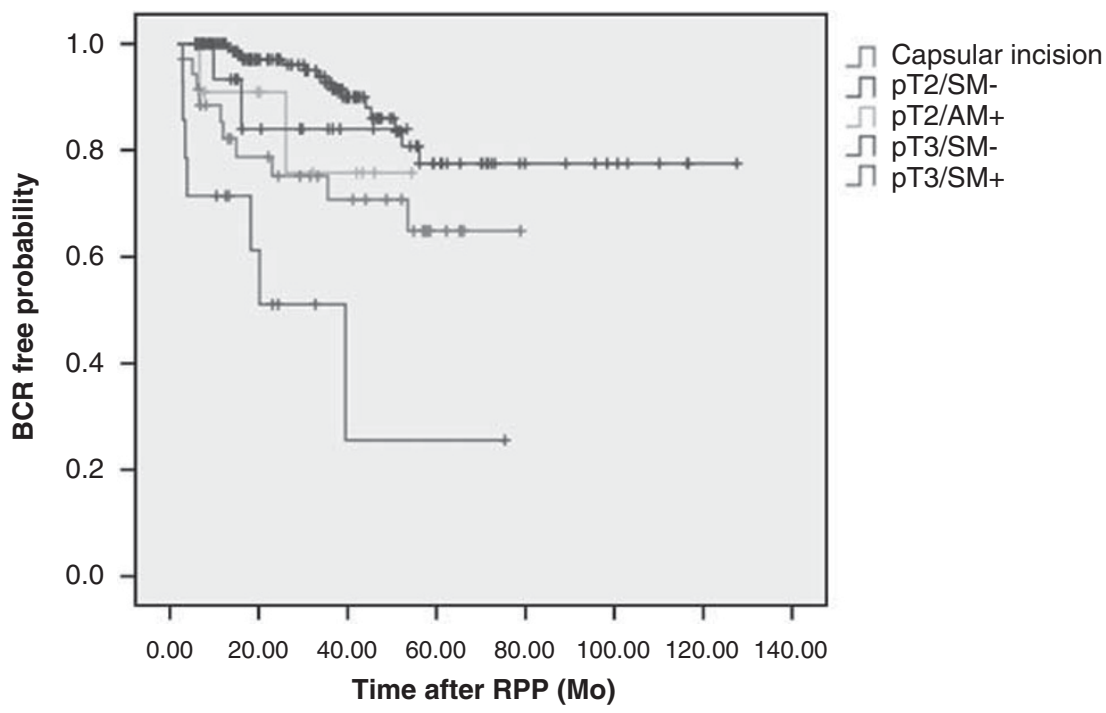

Figure 1 Kaplan-Meier 3-year likelihood of freedom from biochemical recurrence by pathology. BCR, biochemical recurrence; RPP, radical perineal prostatectomy; red, capsular incision; green, organ-confined margin negative; orange, organ-confined apex-only positive margin; purple, extraprostatic extension margin negative; blue, extraprostatic extension margin positive. The color reproduction of this Figure is available on the html full text version of the paper.

with more experience with RPP; this difference was statistically significant $(P=0.024)$ (Figure 2$)$.

\section{Discussion}

Capsular incision is an inadvertent surgical incision through the capsule into the intracapsular cancer. Earlier studies have reported variable frequencies for the occurrence of CI. ${ }^{3-17}$ The disparity may be attributable to differences in surgical technique, definition of $\mathrm{CI}$, the characteristics of the patients studied and the stringency of the pathological analysis. Although the perineal approach has been reported to be more likely than the retropubic approach, to lead to CI with the risk of positive surgical margins in organ-confined tumors because of a limited surgical field, ${ }^{17}$ RPP had pathological results, such as positive surgical margins and CI, similar to retropubic procedures with proper patient selection. $^{4}$
Although an earlier study reported that the anterior prostate was the most common site for surgical margins with the perineal approach, ${ }^{3}$ our results showed that positive surgical margins in the anterior prostate were present in six cases $(2.2 \%)$, including three with organconfined cancer. A possible explanation for this difference is the characteristics of our cohort and the surgical techniques used; we excluded clinical stage T1a and T1b tumors, which have been associated with positive margins at the anterior prostate more frequently. In addition, we carried out sharp division of the puboprostatic ligaments during the anterior dissection to avoid avulsion of the anterior prostate, which can result iatrogenic positive margins as Weldon et al. described earlier. ${ }^{3}$

The nerves that contribute to erectile function course posterolateral to the prostate in the neurovascular bundles that are the most common site of EPE. Despite the belief that the wider the dissection, the lower the chance of a positive surgical margin, cancer control and the risk of a positive surgical margin in nerve-sparing 
procedures is not compromised in appropriately selected patients. ${ }^{18,19}$ Nerve-sparing RPP, in our series, was done on each side for patients that met all of the following criteria: patients with good pre-operative potency, patients who did not have a palpable nodule on rectal examination and a neurovascular bundle that could be easily and clearly dissected off of the prostate during RPP. In a retropubic radical prostatectomy series, most of the iatrogenic posterolateral positive margins in organ-

Table 2 Evaluation of potential risk factors for capsular incision $(n=233)$

\begin{tabular}{|c|c|c|c|c|}
\hline \multirow[t]{2}{*}{ Variables } & \multicolumn{2}{|c|}{ P-value } & \multirow[t]{2}{*}{ Odds ratio } & \multirow{2}{*}{$\begin{array}{c}95 \% \\
C I\end{array}$} \\
\hline & Univariate & Multivariate & & \\
\hline \multicolumn{5}{|l|}{$\begin{array}{l}\text { Pre-operative PSA } \\
\left(n g m l^{-1}\right)\end{array}$} \\
\hline$<10$ & \multirow[t]{2}{*}{0.065} & \multicolumn{3}{|c|}{ Reference } \\
\hline \multirow{2}{*}{\multicolumn{5}{|c|}{$\begin{array}{l}\text { Gleason score at } \\
\text { biopsy specimen }\end{array}$}} \\
\hline & & & & \\
\hline$\leqslant 6$ & \multirow[t]{3}{*}{0.927} & \multicolumn{3}{|c|}{ Reference } \\
\hline 7 & & 0.459 & 0.717 & $0.297-1.731$ \\
\hline$\geqslant 8$ & & 0.446 & 0.647 & $0.212-1.979$ \\
\hline $\begin{array}{l}\text { Prostate volume } \\
(\mathrm{ml})\end{array}$ & 0.023 & 0.083 & 0.973 & $0.942-1.004$ \\
\hline \multicolumn{5}{|l|}{$\begin{array}{l}\text { Nerve-sparing } \\
\text { procedure }\end{array}$} \\
\hline No & \multirow[t]{2}{*}{0.036} & \multicolumn{3}{|c|}{ Reference } \\
\hline Yes & & 0.173 & 0.530 & $0.213-1.321$ \\
\hline \multicolumn{5}{|l|}{$\begin{array}{l}\text { \% of positive core } \\
\text { at biopsy }\end{array}$} \\
\hline$\leqslant 25 \%$ & \multirow[t]{2}{*}{0.014} & \multicolumn{3}{|c|}{ Reference } \\
\hline$>25 \%$ & & 0.039 & 2.333 & $1.045-5.211$ \\
\hline $\begin{array}{l}\text { Number of surgery } \\
\text { experienced }\end{array}$ & 0.016 & 0.018 & 0.398 & $0.185-0.856$ \\
\hline
\end{tabular}

Abbreviations: CI, Confidence interval; PSA, prostate-specific antigen. confined tumors were attributed to attempts at nervesparing procedures. ${ }^{20}$ In this study, among the 96 men who underwent a nerve-sparing RPP, either unilateral or bilateral, CI of the posterolateral aspect, where the nerves were spared ipsilaterally, occurred in five $(5.2 \%)$ patients. The nerve-sparing procedure was not a predictive risk factor for CI in this study. This finding suggests that the dissection of the posterolateral aspect is more accessible with the perineal approach than the retropubic approach.

Janoff and Parra ${ }^{6}$ recommended to avoid RPP in patients with a prostate larger than $60 \mathrm{ml}$, as a large prostate can limit the visibility of the operative field, resulting in a positive surgical margin. However, 15 of our patients had a prostate larger than $60 \mathrm{ml}$, and none of them had surgery-related complications perioperatively. Only one patient out of 15 with a prostate larger than $60 \mathrm{ml}$ had CI on the RPP pathology. In addition, the results of our study showed that the prostate size was not a significant predictive risk factor for CI. This finding suggests that larger prostates are less likely than expected to affect the operative field with the perineal approach. The result that the risk for CI was not associated with nerve-sparing procedure, but with the percentage of positive biopsy cores is remarkable if larger volume cancers on biopsy are likely to have fewer attempts at nerve-sparing procedure. This result seems to mean that CI is not related to attempt at nerve-sparing procedure if appropriately selected.

Some earlier studies ${ }^{14,15}$ found no prognostic significance associated with CI. However, this study is different in terms of the characteristics of the study cohort and the definition of CI. We excluded men with positive lymph nodes and seminal vesicle invasion, signifying minimal possibility of cure. In the analysis of our study, the tumor volume of the RPP specimen (data not shown) was not included because the tumor volume was not an independent prognostic factor by multivariate analysis. ${ }^{21,22}$

The limitations of our study include the following. First, the number of patients in our cohort was small and the follow-up was relatively short. Nevertheless, the results of our study already showed a significant

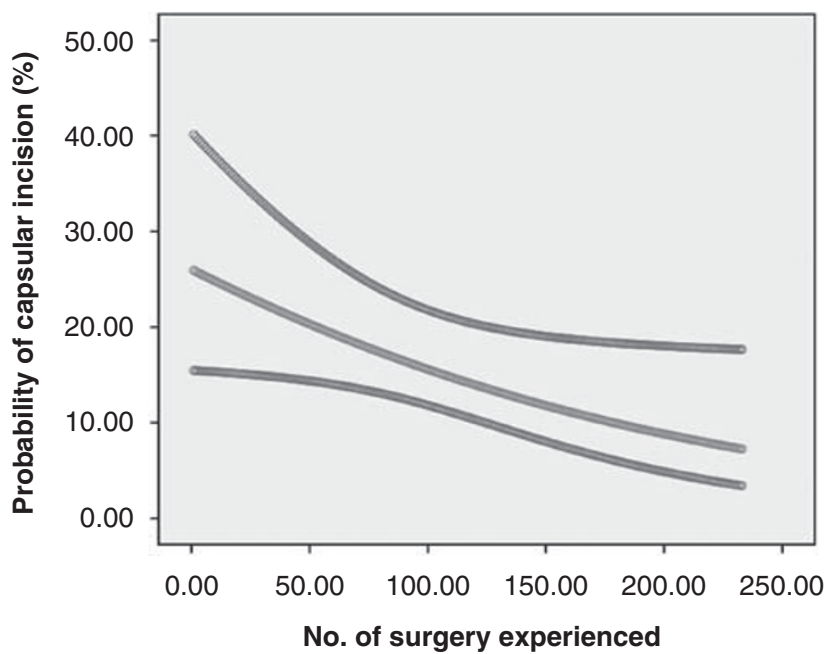

Figure 2 Probability over time of capsular incisions. Red, probability of capsular incision; blue, $95 \%$ confidence interval; $P=0.024$. The color reproduction of this Figure is available on the html full text version of the paper. 
difference in BCR between CI and pT2/SM- and pT3a/ $\mathrm{SM}+$ groups. Second, we analyzed positive margins and EPE without assessing their extent. However, there is no standardized method for subdividing these findings into focal versus non-focal types. Third, this study was limited to the experience of a single surgeon at a single tertiary institution. However, this study is one of the few studies to evaluate the impact of CI on BCR and, to our knowledge, the first to identify the risk factors associated with CI in patients treated by RPP.

Although RPP in special cases has been shown to have more acceptable results for the perioperative outcomes, ${ }^{23-25}$ it is not a common procedure familiar to urologists at most urological training centers. In contrast to retropubic approach, the procedure of RPP is initiated at the plane between the posterior aspect of prostate and Denonvillier's fascia. Maneuver with instruments inserted transurethrally, such as a curved Lowsley retractor and a straight Young retractor, aids to elevate and deliver the prostate and seminal vesicle during dissection. These might not cause the artefactual incisions during dissection. As reported earlier, ${ }^{26-28}$ improved visualization of the junction between the rectum and prostate by initial release of the lateral pelvic fascia and early dissecting the prostate off the rectum leads to permit precise delineation on the anatomy around the prostate and to prevent leaving small amounts of prostatic tissue. Ultimately, it results in a lower rate of positive surgical margin. This technique is true of the procedure of RPP, alluding to the advantage of perineal approach. The results of our study suggest that $\mathrm{CI}$ have a higher $\mathrm{BCR}$ rate than organconfined disease, and that they are significantly associated with the percentage of positive biopsy cores. The rate of $\mathrm{CI}$ over time significantly decreased, indicating the importance of the surgeon's experience with CI. To reduce the occurrence of CI, surgeons should consider the proportion of positive biopsy cores and use the most appropriate surgical technique for each patient.

\section{Conclusions}

The results of this study show that CI adversely affected the prognosis of patients with prostate cancer and were likely to occur in proportion to positive biopsy cores. In cases with cancers with multiple positive cores, which suggest a larger tumor volume, meticulous dissection is necessary to avoid CI during RPP.

\section{Conflict of interest}

The authors hereby certify that this is an original, unpublished work that is not under consideration elsewhere. The authors declare no conflict of interest.

\section{References}

1 Young $\mathrm{HH}$. The early diagnosis and radical cure of carcinoma of the prostate. Bull Johns Hopkins Hosp 1905; 16: 315-321.

2 Weldon VE, Tavel FR. Potency-sparing radical perineal prostatectomy: anatomy, surgical technique and initial results. J Urol 1988; 140: 559-562.
3 Weldon VE, Tavel FR, Neuwirth H, Cohen R. Patterns of positive specimen margins and detectable prostate specific antigen after radical perineal prostatectomy. J Urol 1995; 153: 1565-1569.

4 Korman HJ, Leu PB, Huang RR, Goldstein NS. A centralized comparison of radical perineal and retropubic prostatectomy specimens: is there a difference according to the surgical approach? J Urol 2002; 168: 991-994.

5 Harris MJ. Radical perineal prostatectomy: cost efficient, outcome effective, minimally invasive prostate cancer management. Eur Urol 2003; 44: 303-308; discussion 308.

6 Janoff DM, Parra RO. Contemporary appraisal of radical perineal prostatectomy. J Urol 2005; 173: 1863-1870.

7 Shuford MD, Cookson MS, Chang SS, Shintani AK, Tsiatis A, Smith Jr JA et al. Adverse prognostic significance of capsular incision with radical retropubic prostatectomy. J Urol 2004; 172: 119-123.

8 Nelson JB, Lepor H. Prostate cancer: radical prostatectomy. Urol Clin North Am 2003; 30: 703-723, viii.

9 Kausik SJ, Blute ML, Sebo TJ, Leibovich BC, Bergstralh EJ, Slezak J et al. Prognostic significance of positive surgical margins in patients with extraprostatic carcinoma after radical prostatectomy. Cancer 2002; 95: 1215-1219.

10 Swindle P, Eastham JA, Ohori M, Kattan MW, Wheeler T, Maru N et al. Do margins matter? The prognostic significance of positive surgical margins in radical prostatectomy specimens. J Urol 2005; 174: 903-907.

11 Pettus JA, Weight CJ, Thompson CJ, Middleton RG, Stephenson RA. Biochemical failure in men following radical retropubic prostatectomy: impact of surgical margin status and location. J Urol 2004; 172: 129-132.

12 McAleer SJ, Schultz D, Whittington R, Malkowicz SB, Renshaw A, Wein A et al. PSA outcome following radical prostatectomy for patients with localized prostate cancer stratified by prostatectomy findings and the preoperative PSA level. Urol Oncol 2005; 23: 311-317.

13 Cheng L, Darson MF, Bergstralh EJ, Slezak J, Myers RP, Bostwick DG. Correlation of margin status and extraprostatic extension with progression of prostate carcinoma. Cancer 1999; 86: 1775-1782.

14 Ohori M, Wheeler TM, Kattan MW, Goto Y, Scardino PT. Prognostic significance of positive surgical margins in radical prostatectomy specimens. J Urol 1995; 154: 1818-1824.

15 Barocas DA, Han M, Epstein JI, Chan DY, Trock BJ, Walsh PC et al. Does capsular incision at radical retropubic prostatectomy affect disease-free survival in otherwise organ-confined prostate cancer? Urology 2001; 58: 746-751.

16 Stamey TA, Villers AA, McNeal JE, Link PC, Freiha FS. Positive surgical margins at radical prostatectomy: importance of the apical dissection. J Urol 1990; 143: 1166-1172; discussion 1172-1163.

17 Boccon-Gibod L, Ravery V, Vordos D, Toublanc M, Delmas V, Boccon-Gibod L. Radical prostatectomy for prostate cancer: the perineal approach increases the risk of surgically induced positive margins and capsular incisions. J Urol 1998; 160: 1383-1385.

18 Sofer M, Hamilton-Nelson KL, Schlesselman JJ, Soloway MS. Risk of positive margins and biochemical recurrence in relation to nerve-sparing radical prostatectomy. J Clin Oncol 2002; 20: 1853-1858.

19 Ward JF, Zincke H, Bergstralh EJ, Slezak JM, Myers RP, Blute ML. The impact of surgical approach (nerve bundle preservation versus wide local excision) on surgical margins and biochemical recurrence following radical prostatectomy. J Urol 2004; 172: $1328-1332$

20 Rosen MA, Goldstone L, Lapin S, Wheeler T, Scardino PT. Frequency and location of extracapsular extension and positive surgical margins in radical prostatectomy specimens. J Urol 1992; 148: 331-337.

21 Salomon L, Anastasiadis AG, Antiphon P, Levrel O, Saint F, De La Taille A et al. Prognostic significance of tumor volume after radical prostatectomy: a multivariate analysis of pathological prognostic factors. Eur Urol 2003; 43: 39-44. 
22 Epstein JI, Carmichael M, Partin AW, Walsh PC. Is tumor volume an independent predictor of progression following radical prostatectomy? A multivariate analysis of 185 clinical stage B adenocarcinomas of the prostate with 5 years of followup. J Urol 1993; 149: 1478-1481.

23 Boczko J, Melman A. Radical perineal prostatectomy in obese patients. Urology 2003; 62: 467-469.

24 Dahm P, Yang BK, Salmen CR, Moul JW, Gan TJ. Radical perineal prostatectomy for the treatment of localized prostate cancer in morbidly obese patients. J Urol 2005; 174: 131-134.

25 Freedland SJ, Grubb KA, Yiu SK, Nielsen ME, Mangold LA, Isaacs $\mathrm{WB}$ et al. Obesity and capsular incision at the time of open retropubic radical prostatectomy. J Urol 2005; 174: 1798-1801; discussion 1801

26 Stephenson RA, Middleton RG, Abbott TM. Wide excision (nonnerve sparing) radical retropubic prostatectomy using an initial perirectal dissection. J Urol 1997; 157: 251-255.

27 Klein EA, Kupelian PA, Tuason L, Levin HS. Initial dissection of the lateral fascia reduces the positive margin rate in radical prostatectomy. Urology 1998; 51: 766-773.

28 Richman M, McLaughlin S, Maygarden S, Pruthi RS. Initial incision of lateral pelvic fascia and early ligation of vascular pedicles during radical prostatectomy: potential to reduce positive margin rates. BJU Int 2005; 95: 40-45. 